\title{
Enhancement of peptide immunogenicity by insertion of a cathepsin $B$ cleavage site between determinants recognized by $B$ and $T$ cells
}

\author{
P. Sarobe (1), J.-J. Lasarte (1), E. Larrea (1), J.-J. Golvano (1), I. Prieto (1), A. Gullón (2), \\ J. Prieto ${ }^{(1)}$ and F. Borrás-Cuesta ${ }^{(1)}\left(^{*}\right)$ \\ (1) Departamento de Medicina Interna, Universidad de Navarra, Facultad de Medicina, and ${ }^{(2)}$ Departamento \\ de Genética, Universidad de Navarra, Facultad de Medicina, Apartado 273, 31008 Pämplona (Spain)
}

\section{SUMMARY}

The insertion of two lysine residues (cleavage sites of cathepsin $B$ ) at the boundary of a peptide recognized by $B$ cells $(B D)$ and a class-II- presentable sequence $\left(T D_{h}\right.$ ) enhanced the anti-BD antibody induction capacity of this type of peptide construct, as well as production of IL2. It is postulated that these lysines generate a neoprocessable site which helps in release of the $T_{h}$ moiety from the construct, enabling its presentation to class II molecules, an essential step in clonal expansion of the antibodyproducing $B$ cell after internalization of the construct via the BD moiety.

Key-words: Immunogenicity, Peptide, Lysine, B cell, T cell, IL2 ; Determinant, Cathep$\sin B$, Antigen processing.

\section{INTRODUCTION}

Immunization experiments with peptide chimeras, consisting of a B-cell epitope (BD) colinearly linked to a class-II-presentable $\mathrm{T}$ helper peptide $\left(\mathrm{TD}_{\mathrm{h}}\right)$, have shown that the immunogenicity of the construct and the specificity of the antibody response induced are dependent on the relative positions of the $\mathrm{BD}$ and $\mathrm{TD}_{\mathrm{h}}$ in the chimera (Cox et al., 1988; Levely et al., 1990; Golvano et al., 1991). These differences in response may be due to changes in the processing and/or structure of these constructs.

Beccuse pairs of basic residues (KK, KR, RR) are the main cleavage sites of cathepsin B, one of the most important enzymes for antigen processing in the context of class II molecules (Takahashi et al., 1989), we speculated that the insertion of a pair of lysine residues at the boundary of the BD and $T D_{h}$ moieties of a poorly immunogenic $B D-T_{h}$ construct might improve the immunogenecity of this construct. Moreover, an insight into the effect of surface exposure of the moieties upon the specificity of the antibodies induced might be obtained by measuring the recognition of the chimeras by anti-BD and anti-TD ${ }_{h}$ antibodies. The results of these experiments are shown below. 


\section{MATERIALS AND METHODS}

\section{Peptide synthesis}

Peptides were synthesized by the solid phase method of Merrifield (Merrifield, 1963) using the Fmoc alternative (Atherton et al., 1981). Synthesis was carried out manually and the ninhydrin test of Kaiser (Kaiser et al., 1970) used to monitor every step. Couplings were repeated if necessary until a negative ninhydrin test was attained. All peptides were purified by HPLC (high performance liquid chromatography) on a reverse phase $\mathrm{C} 18$ column.

\section{Immunization experiments}

Groups of three 4-week-old BALB/c female mice were immunized by i.p. injection of $200 \mu$ l of an emulsion obtained by sonication of $100 \mu \mathrm{l}$ of complete Freund's adjuvant and $100 \mu \mathrm{l}$ of saline solution containing $60 \mu \mathrm{g}$ of peptide antigen, and boosted at days 30 and 45 with the same dose of antigen in incomplete Freund's adjuvant. Mice were bled from the orbital sinus on days 30,45 , and 60 after the first injection.

\section{Titration of antibodies}

Anti-peptide antibodies were titrated by ELISA as described (Golvano et al., 1990). Basically, microtitre wells (Nunc, Denmark) were coated with peptides by incubation with $50 \mu$ l of peptide solutions at $4^{\circ} \mathrm{C}$ overnight $(20 \mu \mathrm{g} / \mathrm{ml}$ of peptide in $0.1 \mathrm{M}$ sodium carbonate buffer, $\mathrm{pH} 10.5$ ). The wells werc washed with phosphate buffer saline, $\mathrm{pH} 7.6$ containing $1 \%$ powdered milk and $0.1 \%$ Tween 20 (PBSMT), and incubated with this buffer for $1 \mathrm{~h}$ at room temperature to block non-specific antibody binding. After removing the PBSMT, $50 \mu l$ of different serum dilutions were added and incubated at $37^{\circ} \mathrm{C}$ for $1 \mathrm{~h}$ (for the peptide inhibition experiments, the serum was pre incubated with peptide at $37^{\circ} \mathrm{C}$ for $1 \mathrm{~h}$ ). Following the addition of goat anti-mouse IgG biotinylated whole antibody (Amersham, UK) and horseradish peroxidase-streptavidin (Amersham, UK), the colour reaction was started by adding $40 \mathrm{mM}$ of ABTS (2,2'-azino-bis(3-ethylbenzthiazoline-6-sulphonic acid) in water. After $30 \mathrm{~min}$, plates were read at $405 \mathrm{~nm}$ in a "Titertek Multiskan" MKII (Flow laboratories). Endpoint antibody titres were expressed as the highest dilution giving 3 times the optical density of the preimmune serum.

\section{IL2 production assay}

Mice were immunized at the base of the tail and footpads with peptide (100 $\mu \mathrm{g} /$ mouse) in complete Freund's adjuvant (1:1). Ten days after the primary injection, animals were killed and lymph node cells wcre removed. The lymphocytes were then plated on 96-well plates (Costar) at $5 \times 10^{5}$ cells/well with RPMI-supplemented medium (RPMI supplemented with $10 \%$ foetal calf serum, $10 \mathrm{mM}$ glutamine, penicillin $100 \mathrm{U} / \mathrm{ml}$, streptomycin $100 \mathrm{mg} / \mathrm{ml}$ and $5 \times 10^{-5} \mathrm{M}$ 2-mercaptoethanol) or serial dilutions of peptides in $0.2 \mathrm{ml}$ final volume. Supernatants $(50 \mu \mathrm{l})$ were removed $24 \mathrm{~h}$ later and assayed for the IL2 content as described (Lai et al., 1987). Results are presented as a stimulation index, which is the ratio of the mean (three determinations) cpm incorporated in the presence of antigen to the mean (three determinations) cpm obtained in the absence of antigen.

\section{RESULTS}

\section{Humoral immune response}

It has been shown (Golvano et al., 1990) that the immunogenicity of peptide constructs FISEAIIHVLHSRLKCNNKTFNGTGPCTNV (FIS-LKC) and LKCNNKTFNGTGPCTNVFISEAIIHVLHSR (LKC-FIS) depends on the relative orientation of LKC and FIS. These two moieties are from HIVl envelope protein (WainHobson et al., 1985) and sperm whale myoglobin, respectively. LKC has a haptenic character (Golvano et al., 1990), whereas FIS is a $\mathrm{TD}_{\mathrm{h}}$ in BALB/c mice (Cease et al., 1986). The construct FIS-LKC induced high antibody titres against LKC and none against FIS, whereas the construct LKC-FIS was much less immunogenic and gave low antibody titres against both LKC and FIS.

\footnotetext{
ABTS $=2,2^{\prime}$-azino-bis(3-ethylbenz-thiazoline-6-sulphonic acid).

$\mathrm{BD}=\mathrm{B}$ determinant.

$\mathrm{cpm}=$ counts per minute.
}

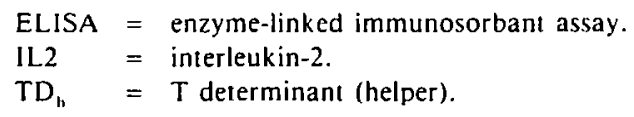


To test whether the immunogenicity of peptide LKC-FIS might be enhanced by insertion of a cathepsin B cleavage site between the B-cell and $T$-cell epitopes, we synthesized the peptide LKCNNKTFNGTGPCTNVKKFISEAIIHVLHSR (LKC-KK-FIS) which contains two extra lysines (in bold). This peptide was used to immunize BALB/c mice in order to compare its immunogenicity with that of LKC-FIS and FIS-LKC.

The antibody titres at day 60 induced by FISLKC, LKC-FIS and LKC-KK-FIS were measured by ELISA against the whole antigens and against the FIS and LKC moieties (table I). With the exception of FIS-LKC, which induced antibodies against the LKC moiety only, the constructs LKC-FIS and LKC-KK-FIS induced antibodies against both moieties. Titration of anti-LKC antibodies using LKC adsorbed on the ELISA plate showed that constructs FIS-LKC, LKC-KK-FIS and LKC-FIS induced anti-LKC antibodies with titres of $250,000,85,000$ and 2,400 respectively. These results show that the insertion of two lysine residues at the boundary between LKC and FIS (to give LKC-KKFIS)dramatically improved the induction of antiLKC antibodies compared to those induced by unmodified LKC-FIS.

Titration of anti-FIS antibodies was done using FIS adsorbed on the ELISA plate. FIS-LKC did not induce anti-FIS antibodies, whereas LKC-KK-FIS induced high anti-FIS titres.

\section{Accessibility of peptide moieties to antibody recognition}

The degree of "accessibility" of LKC and FIS in constructs FIS-LKC, LKC-FIS and LKC-KKFIS to antibody recognition was measured by titrating anti-FIS antibodies (induced by free FIS) and anti-LKC antibodies (induced by FERLKC) (Golvano et al., 1990) against these three constructs adsorbed on the ELISA plate (table II). These titrations showed that FIS is poorly exposed for antibody recognition in FIS-LKC and well exposed in LKC-FIS and LKC-KK-FIS. Also, the LKC moiety is well exposed in FISLKC and less well exposed in LKC-FIS and LKC-KK-FIS.
Table I. Antibody titres $\left({ }^{*}\right)\left(\times 10^{-3}\right)$ induced by three different immunogens.

\begin{tabular}{lccc} 
& \multicolumn{3}{c}{ Titre against: } \\
Immunogen & self & FIS & LKC \\
\hline FIS-LKC & 500 & 0 & 250 \\
LKC-FIS & 70 & 2.6 & 2.4 \\
LKC-KK-FIS & 900 & 170 & 85 \\
\hline
\end{tabular}

(*) Titres shown are means from three different mice.

Titrations were carried out against self (the whole immunogen) and against FIS and LKC.

Table II. Recognition antibody titres $\left({ }^{*}\right)\left(\times 10^{-3}\right)$ of FIS and LKC in three different peptide constructs by antisera specific for each of these moieties.

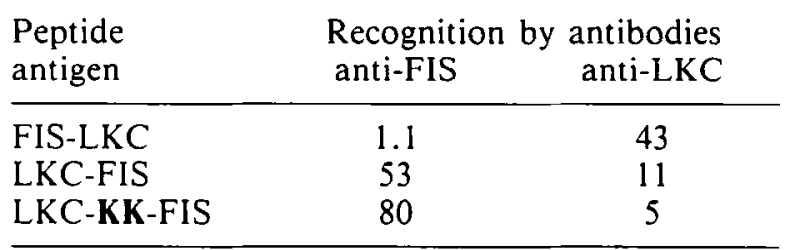

${ }^{*}$ ) Titres shown are means from three different mice. Anti-FIS and anti-LKC antibodies were induced with free FIS and FER-LKC, respectively.

The degree of accessibility of FIS in the different peptide constructs was also measured using a competition assay in solution. Thus, solutions of FIS, LKC-FIS, FIS-LKC or LKC-KK-FIS were incubated with an anti-FIS antiserum and we measured the recognition of FIS adsorbed on the plate (table III). These experiments showed that FIS-LKC is the sole peptide that is unable to inhibit this recognition, proving that FIS in FIS-LKC is the least accessible for antibody recognition. This result is in agreement with those obtained by direct recognition of FIS from the different peptide constructs adsorbed on the ELISA plate, shown in table II.

\section{Antigen processing}

To gain an insight into how antigenpresenting cells process peptide constructs LKCFIS, FIS-LKC and LKC-KK-FIS, we immunized 
BALB/c mice with free FIS as described in Materials and Methods. After removal of the lymph nodes and plating of the lymphocytes, these were restimulated with different concentrations of FIS, LKC-FIS, FIS-LKC, LKC-KKFIS and without peptide for $24 \mathrm{~h}$. The IL2 content of these media was then measured as described (Lai et al., 1987). Figure 1 shows that the higher levels of IL2 were induced by LKCKK-FIS followed by FIS-LKC, LKC-FIS and FIS.

\section{DISCUSSION}

Three important events define the humoral response to an antigen: (1) recognition of epi-

Table III. Inhibition (\%) of an anti-FIS antiserum $(1 / 300)$ with FIS-containing peptides.

\begin{tabular}{cc}
$\begin{array}{c}\text { Peptides }(25 \mu \mathrm{g} / \mathrm{ml}) \\
\text { containing FIS }\end{array}$ & $\begin{array}{c}\% \text { Inhibition } \\
\text { of anti-FIS antiserum }\end{array}$ \\
\hline FIS & 50 \\
LKC-FIS & 36 \\
FIS-LKC & 1 \\
LKC-KK-FIS & 63 \\
\hline
\end{tabular}

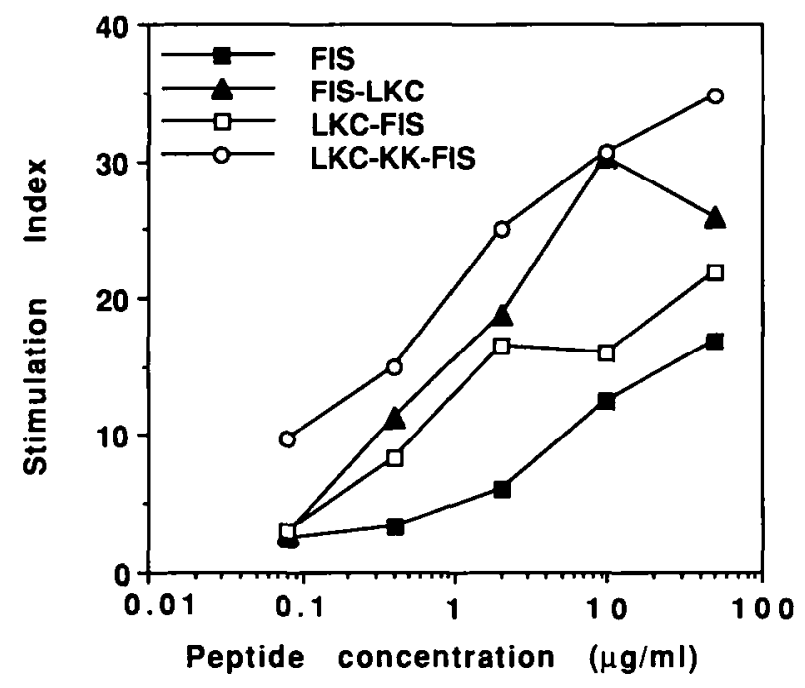

Fig. 1. IL2 production by FIS-immunized BALB/c mice after in vitro restimulation of lymph node cells with the immunogens shown. topes at the surface of the antigen by immunoglobulins of B cells, (2) processing of the antigen by the antigen-presenting cell, to free a $\mathrm{TD}_{\mathrm{h}}$ moiety and enable its binding to class II molecules and (3) recognition of the complex $\mathrm{TD}_{\mathrm{h}}$-class-II molecules by the $\mathrm{T}$-cell receptor of a $T$ helper lymphocyte. From previous work, it was know (Golvano et al., 1990) that the outcome of immunization with peptide constructs FIS-LKC and LKC-FIS was markedly different, both with respect to the immunogenicity of these peptides and to the specificity of the antibodies induced. We speculated that the immunogenicity of LKC-FIS might be enhanced by inserting a cleavage site between the LKC and FIS moieties. Thus, we synthesized the peptide LKC-KKFIS, which contains a pair of lysines (in bold) that are a cleavage site of cathepsin B, an important enzyme responsible for antigen processing in the context of class II molecules (Takahashi et al., 1989). Antibody induction and IL2 production experiments with these three peptides were carried out to study the outcome of the immune response. Using antibodies specific for LKC and FIS, we were able to gain an insight into the accessibility of these moieties to antibody recognition in the three immunogens, and corrclatc this accessibility with the humoral response. These results are discussed below in more detail.

\section{Antibody response after immunization with en- gineered peptide constructs}

The construct FIS-LKC induced high antibody titres against LKC and none against FIS. The absence of anti-FIS antibodies may be explained by assuming that FIS is "hidden" for aptibody recognition in FIS-LKC. Indeed, as shown in table II, anti-FIS antibodies recognize FIS-LKC poorly, in contrast with the recognition of LKC-FIS and of LKC-KK-FIS. Moreover, FIS-LKC is well recognized by anti(FER-LKC), proving that the low titre of antiFIS antibodies, measured against FIS-LKC, is not due to poor binding of FIS-LKC to the ELISA plate. Thus, in FIS-LKC, the FIS moirty is poorly accessible to antibodies, whereas the LKC 
moiety is well presented for antibody recognition. Internalization of FIS-LKC via the LKC may enable easy processing of the construct to free FIS for binding to class II molecules.

The low anti-LKC and anti-FIS antibody titres induced by LKC-FIS (table I) may be due to poor processing of LKC-FIS after internalization (either via the LKC or FIS moieties) to give available FIS for binding to class II molecules. Since, in LKC-FIS, the antibody titres against the whole antigen are much higher than against the FIS and LKC moieties (table I), we favour the hypothesis that LKC-FIS is recognized and internalized preferentially via one or more epitopes simultaneously encompassing parts of LKC and FIS. The titre against the whole antigen LKC-FIS is much lower than the corresponding titres induced by FIS-LKC and LKC-KK-FIS. Since antibodies against LKC and FIS were induced after immunization with LKCFIS, both moieties are also accessible for antibody recognition. This is confirmed by results of table II, which show that they are recognized by the corresponding antibodies.

The construct LKC-KK-FIS induced antibodies against LKC and FIS with titres of 85,000 and 170,000 respectively. This shows that LKC and FIS are surface-exposed, as confirmed by the ability of anti-FIS and anti-LKC antibodies to recognize LKC-KK-FIS (table II).

\section{Processing of peptides by the antigen-presenting cells}

The results of IL2 production shown in figure 1 provide an insight into how FIS is visualized following processing of FIS-LKC, LKC-FIS and LKC-KK-FIS by antigen-presenting cells. LKCKK-FIS and FIS-LKC induced higher levels of IL2, followed by LKC-FIS and FIS. The finding that LKC-KK-FIS induced higher levels of IL2 than LKC-FIS suggests that LKC-KK-FIS is better processed than LKC-FIS, in agreement with our original hypothesis that insertion of a putative cathepsin B cleavage site between the hapten and the $\mathrm{TD}_{\mathrm{h}}$ moiety might enhance the immunogenicity of the peptide. The two lysines may render this construct more immunogenic than LKC-FIS due to improved processing of LKC-KK-FIS to liberate FIS for class II binding. However, since cathepsin B may not be the sole relevant enzyme in class II processing, it cannot be excluded that this improved processing may be related to other enzymes. Moreover, the increase in immunogenicity may also be partly duc to the structural change induced by the two added lysines, which may render both moieties (FIS and LKC) more accessible to antibody recognition.

The levels of IL2 after restimulation with free FIS were unexpectedly low, especially when considering that the mice had been immunized with free FIS. A tentative explanation may be that, after internalization of FIS by an immunoglobulin, FIS may not be efficiently released for binding to class II molecules, a situation that has been described for other antigens (Ozaki and Berzofsky, 1987; Manca et al., 1988). However, the internalization of constructs FIS-LKC, LKCKK-FIS and LKC-FIS may take place via the LKC moiety, leaving FIS more accessible for processing. If a "cleavable" site between FIS and LKC exists, then FIS might bind more efficiently to newly synthesized class II molecules inside the cell than to empty class II molecules exposed at the surface of the antigen-presenting cells (Neefjes and Ploegh, 1992).

In conclusion, the insertion of a cathepsin B cleavage site between the BD and $\mathrm{TD}_{\mathrm{h}}$ moieties of a peptide construct BD-TD $\mathrm{T}_{\mathrm{h}}$ dramatically enhanced the immunogenicity of the peptide. This suggests that improved processing may be related to enhanced immunogenicity. This strategy may prove useful for the design of peptide vaccines.

Our results demonstrate the role of surface exposure (as measured by antibody accessibility) of the $\mathrm{BD}$ and the $\mathrm{TD}_{\mathrm{h}}$ epitopes of peptide constructs in the outcome of specificity of the induced antibodies. We suggest that when repeated immunizations of the same animal or individual are to be carried out, the ideal construct should have the $T D_{h}$ hidden from antibody recognition to avoid induction of anti-TD $\mathrm{T}_{h}$ antibodies. This would ensure the absence of competition for the antigen between the 
populations of B lymphocytes specific for the $\mathrm{BD}$ and $\mathrm{TD}_{\mathrm{h}}$ moieties respectively. Thus, the desired anti-BD antibodies would be preferentially induced.

\section{Acknowledgements}

We thank the Gobierno de Navarra, the Fundacion Ramón Areces and the Comisión de Investigación Ciencia Tecnologiả (C.I.C.Y.T.), Spain for financial support.

\section{Augmentation de l'immunogénicité d'un peptide par insertion d'un site de clivage de la cathepsine $B$ entre les déterminants reconnus par les lymphocytes $B$ et $T$}

L'insertion de 2 résidus lysine (sites de clivage de la cathepsine B) à la frontière d'un peptide reconnu par les cellules $B(B D=B$ determinant) et d'une séquence "présentable» de classe II (TD ${ }_{h}=T$ determinant helper), augmente la capacité pour ce type de construction peptidique d'induire des anticorps anti-BD ainsi que la production d'IL2. L'hypothèse est que ces résidus lysine génèrent un site de néoprocessus qui contribue à la libération de la moitié $T D_{h}$ de la construction, rendant possible sa présentation aux molécules de classe II, étape essentielle pour le développement clonal des lymphocytes B produisant des anticorps après internalisation de la construction via la moitié $B D$.

Mots-clés: Immunogénicité, Peptide, Lysine, Lymphocyte B, Lymphocyte T, IL2; Déterminant, Cathepsine B.

\section{References}

Atherton, E., Logan, J.C. \& Sheppard, C.R. (1981), Peptide synthesis. - II. Procedures for solid phase synthesis using $\mathrm{N}$-fluorenil metoxicarbonil amino acids on polyamide supports. Synthesis of substance $P$ and of acyl carrier protein 65-74 decapeptide. J. Chem. Soc. Perkin. Trans., 1, 538-546.

Cease, K.B., Berkower, I., York-Jolley, J. \& Berzofsky, J.A. (1986), T-cell clones specific for an amphipathic alpha-helical region of sperm whale myoglobin show differing fine specificities for synthetic peptides: a multi-view single structure interpretation of immunodominance. J. Exp. Med., 164, 1779-1784.

Cox, J.H., Ivanyi, J., Young, D.B., Lamb, J.R., Syred, A.D. \& Francis, M.J. (1988), Orientation of epitopes influences the immunogenicity of synthetic peptide dimers. Eur. J. Immunol., 18, 2015-2019.

Golvano, J.J., Lasarte, J.J., Sarobe, P., Gullón, A., Prieto, J. \& Borrás-Cuesta, F. (1990), Polarity of immunogens: implications for vaccine design. Eur. $J$. Immunol., 20, 2363-2366.

Kaiser, E., Colescott, R.L., Bossinger, C.D. \& Cook, P.I. (1970), Color test for detection of free terminal amino groups in the solid phase synthesis of peptides. Anal. Biochem., 34, 595-598.

Lai, M.Z., Ross, D.T., Guillet, J.G., Briner, T.J., Gefter, M. \& Smith, J.A. (1987), T-lymphocyte response to bacteriophage $\lambda$ repressor $\mathrm{cl}$ protein. $J$. Immunol., 139, 3973-3980.

Levely, M.E., Mitchell, M.A. \& Nicholas, J.A. (1990), Synthetic immunogens constructed from T-cell and B-cell stimulating peptides ( $T: B$ chimeras): preferential stimulation of unique $\mathrm{T}$ - and $\mathrm{B}$-cell specificities is influenced by immunogen configuration. Cell. Immunol., 125, 65-78.

Manca, F., Fenoglio, D., Kunkl, A., Cambiaggi, C., Sasso, M. \& Celada, F. (1988), Differential activation of $T$-cell clones stimulated by macrophages exposed to antigen complexed with monoclonal antibodies. A possible influence of paratope specificity on the mode of antigen processing. $J$. Immunol., 140, 2893-2898.

Merrifield, R.B. (1963), Solid phase peptide synthesis. I. The synthesis of a tetrapeptide. J. Am. Chem. Soc., $85,2149-2154$.

Neefjes, J.J. \& Ploegh, H.L. (1992), Intracellular transport of MHC class II molecules. Immunol. Today. $13,179-184$.

Ozaki, S. \& Berzofsky, J.A. (1987), Antibody conjugates mimic specific B-cell presentation of antigen : relationship between $\mathrm{T}$ - and B-cell specificity. J. Immunol., 138, 4133-4142.

Takahashi, H., Cease, K.B. \& Berzofsky, J.A. (1988), Identification of proteases that process distinct epitopes on the same protein. J. Immunol., 143, 2221-2229.

Wain-Hobson, S., Sonigo, P., Danos, O., Cole, S. \& Alizon, M. (1985), Nucleotide sequence of the AIDS virus, LAV. Cell, 40, 9-17. 